\title{
The Past as the Future: The Marshallian Approach to Post-Walrasian Econometrics
}

Kevin D. Hoover

\author{
Department of Economics \\ University of California \\ 1 Shields Avenue \\ Davis, California 95616-8578 \\ Tel. (530) 752-2129 \\ Fax (530) 752-9382 \\ E-mail kdhoover@ucdavis.edu
}

Revised, 13 October 2004

Paper prepared for the Middlebury Conference on Post Walrasian Macroeconomics, 30 April - 2 May 2004. I thank David Colander for comments on an earlier version. 


\section{Post-Walrasian Econometrics}

The popular image of the scientific revolution usually pits young revolutionaries against old conservatives. Freeman Dyson (2004, p. 16) observes that, in particle physics in the mid- $20^{\text {th }}$ century, something had to change. But in the revolution of quantum electrodynamics, Einstein, Dirac, Heisenberg, Born, and Schödinger were old revolutionaries, while the winners, Feynman, Schwinger, and Tomonaga, were young conservatives. Post-Walrasian economics is not a doctrine, but a slogan announcing that something has to change. Most of the self-conscious efforts to forge a post-Walrasian economics are due to old radicals. Here I want to explore the space of the young conservative: the future is past, particularly in the methodology of Alfred Marshall's methodological essay, “The Present Position of Economics” (1885). The radical approach identifies the problem as Walrasian theory and seeks to replace it with something better and altogether different. The conservative approach says that theory is not the problem. The problem is rather to establish an empirical discipline that connects theory to the world.

Marshall's methodology places the relationship between theory and empirical tools on center stage. In North America, if not in Europe, the dominant tools of macroeconometrics are the vector autoregression (VAR) and calibration techniques. These techniques reached their current status as the result of two nearly simultaneous reactions to the Cowles-Commission program, which dominated macroeconometrics during the two decades 1950-1970. These are the famous Lucas critique, and the practically influential, if less storied, Sims critique. I will briefly consider the nature of these two critiques and, then, the competing Walrasian and Marshallian visions of the 
role of theory in econometrics. I conclude with some suggestions about how to do Marshallian macroeconometrics.

\section{Two Critiques}

The Cowles-Commission Program

Econometrics rose to self-consciousness in the 1930s in part as the result of the founding of the Econometric Society. Its manifesto called for a discipline that combined economic theory and statistics as the basis for empirical economics (Frisch 1933). Whose rites would be used to solemnize this marriage was a fraught question during the two decades after 1933. ${ }^{1}$ Spanos (1995) argues that there were two models of statistics for economics to draw on.

The first, the theory of errors, was developed for applications in the physical sciences. It presumed a well articulated, and unquestioned, underlying theoretical model. The statistical problem arose because repeated observations, which were never exact, had to be combined to measure unknown parameters in astronomical and geodesic applications (Stigler 1986, ch. 1).

The second was R.A. Fisher's statistical approach to experimental design. Fisher envisaged repeated experiments in which carefully deployed controls permitted a phenomenon to be isolated except for random and unsystematic influences. The statistical problem was to identify the significance of a phenomenon against the random the background of this random variation.

Both the theory of errors and experimental design were clear about the sources of the random processes characterized through their statistics. Both were secure in their

\footnotetext{
${ }^{1}$ Morgan (1990) provides the best general history of econometrics in this period.
} 
applications of probability theory because they dealt with repeated observations of what they could convincingly argue were the same phenomena. The problem for economics, especially for macroeconomic time-series data was that there were no repeated observations or repeated experiments; there was only a single history. ${ }^{2}$

Spanos argues that Haavelmo’s (1944) "Probability Approach in Econometrics” represented a kind of union of the theory of errors and Fisher's experimental approach. Economic theory was used to identify the relevant causal factors in economic structures viewed as a system. The complete articulation of the relevant factors stood in the place of experimental controls. ${ }^{3}$ The economic structure could then be seen as mechanism in which each datum is a realization of a single process, much like the position of the moon measured at different times, rather than as observations from a constantly changing and incommensurable economic reality.

The Cowles Commission, particularly in its monographs of the late 1940s and early 1950s (Koopmans 1950, Hood and Koopmans 1953) developed the theory of identification to the canonical form that can still be found in econometrics textbooks. It set the stage for later developments in the techniques of structural estimation. The Cowles-Commission approach placed great weight on more or less complete theoretical knowledge. In the classic example, data on prices and quantities are some impossible-todisentangle mixture of supply and demand. It is only when theory can convincingly discriminate between factors other than price that affect supply but not demand and vice versa that it is possible to estimate the price-elasticity of supply or of demand.

\footnotetext{
${ }^{2}$ The term "macroeconomics" appeared at roughly the same time as "econometrics," though it is rarely found in the early econometrics literature, even when the subject is the modeling of clearly deals with what we now regard as macroeconomic data.

${ }^{3}$ Also see Morgan (1990, ch. 8) who emphasizes identification as a substitute for controlled experiment.
} 
For all of its stress on the critical importance of a priori theory as the source of identification, the Cowles-Commission was fairly agnostic with respect to just what the content of relevant economic theory would be. In particular, it was not thought obvious that the theory was Walrasian. Indeed, much of the theory lying behind structural models after the Cowles Commission was Keynesian in that it involved relations between aggregates at best loosely connected to explicit assumptions about individual economic behavior.

The measurement of free parameters and the identification of causes was run together in the notion of structural estimation. The Cowles Commission clearly saw econometric models as articulating causal structures (see especially Simon 1953, who explores the relationship between causality and identification). After the early 1950s, even while the Cowles-Commission program flourished, causal language rapidly disappeared from econometric discourse (see Hoover 2004a for a discussion of the reasons)

\section{The Lucas Critique}

To borrow Jevon's assessment of Ricardo: With the publication of "Econometric Policy Evaluation: A Critique” (1976) that able but wrong-headed man, Robert Lucas, shunted the car of economic science onto a wrong line. He faulted the typical macroeconomic theory of the day for paying too little attention to the fact that the economy comprised intentional agents, who responded to incentives and formed plans on the basis of available information. The econometric models used for policy evaluation failed to account for the fact that policy followed patterns discernible by people in the economy. If policymakers used equations describing economic aggregates systematically to guide a 
change in policy, then as people's behavior responded to the new policy, the very equations used to predict its effects would no longer capture that behavior.

Lucas's initial point was neither new nor necessarily radical. ${ }^{4}$ Since Lucas's illustrations attributed the principal source of the difficulty to the formation of expectations, a straightforward response was consistent with the Cowles-Commission program: supplement the economic theory with a good model of aggregate expectation formation (e.g., the rational-expectations hypothesis) and proceed in the usual manner. ${ }^{5}$

Lucas did, however, have a more radical program in mind. The first element of the program was at best hinted at in “Econometric Policy Evaluation” but was clearly articulated in “Understanding Business Cycles” (Lucas 1977) and in his lectures Models of Business Cycles (1987). The goal of economic theory is to provide an economic model that accurately mimics the economy. A good model is one that would pass the test of the Adelmans - a test similar to the Turing test for machine intelligence - if an econometrician having only the data from the model and the data from the economy cannot tell which is which, then the model is a good one (Adelman and Adelman 1959). ${ }^{6}$

The second element stakes a claim to the particular theoretical base on which models should be built. Lucas seeks the economically invariant in the tastes and technology of the underlying agents in the economy. He argues that these should be analyzed as a complete Walrasian model. In practice, this means not a model of every agent in the economy, but a representative-agent model - one that takes the form of a Walrasian economy with only one agent or a few types of agents standing for all the rest.

\footnotetext{
${ }^{4}$ His precursors include Marschak (1953), one of the key players in the Cowles-Commission program.

${ }^{5}$ This was the program implemented vigorously by Hansen and Sargent (1980). For later developments along these lines, see Ingram (1995).

${ }^{6}$ See Hoover (1995) for a methodological appraisal of calibration and Lucas's conception of modeling.
} 
The case for adopting the representative-agent, Walrasian model is never made fully explicit. It is, in part, a technical one: this is the only model that theorists have worked out more or less completely. But the wholeheartedness of the embrace also has a religious quality to it. It is a leap faith. Modern economists, at least since Adam Smith, have agreed that economic behavior was shaped by individual human choices in the face of changing incentives and constraints. The Walrasian model was a particularly stark representation of that observation. Lucas conveys the feeling, that if we do not hold to the Walrasian creed, then what? Chaos perhaps.

The third element is an ambition. The ideal model is Walrasian, judged by the test of the Adelman's, and is complete. Lucas (1980, p. 288) sees a model without free parameters as the perfect model. In this, he abandons the elements of Fisher's experimental method that are preserved in the Cowles-Commission program and more or less completely embraces the theory of errors as the statistical basis for econometrics. Ideally, economics is about a perfect theoretical characterization in which errors of observation are shrunk to zero. It is this attitude that explains the rise of calibration, particularly in the work of Kydland and Prescott and their followers and Lucas's embrace of it. ${ }^{7}$ Calibration takes theory to be paramount to the point of questioning the data before questioning the theory when there is a discrepancy (Prescott, 1986). It eschews statistical estimation of parameters. And it evaluates its success by matching simulated moments of the calibrated model to the moments of data in the same spirit as the test of the Adelmans.

\section{The Sims Critique}

\footnotetext{
${ }^{7}$ Kydland and Prescott (1982); Lucas (1987). See also Hoover (1995), Hartley, Hoover, and Salyer (1998).
} 
In contrast to Lucas's call for redoubled devotion to a set of fundamentalist theoretical principles, Christopher Sims’s (1980) “Macroeconomics and Reality” appears to be a Nietzschean declaration that the god of the Cowles-Commission is dead. Sims's critique was straightforward: Structural estimation in the Cowles-Commission program requires a priori theory to secure identification. Identification was largely achieved through the exclusion of variables from particular equations (zero restrictions). Such identification was literally "incredible" - that is, no one real believed that there were good theoretical grounds for the exclusions that were routinely made. The commitment to identification was little more than the empty forms of piety.

Honesty, Sims argued, requires that we give up on structural estimation and do what we can without unsupported identifying assumptions. He advocated analyzing vector autoregressions (VARs), which are equations of the form:

$$
\mathbf{Y}_{t}=\mathbf{B}(L) \mathbf{Y}_{t-1}+\mathbf{U}_{t}
$$

where $\mathbf{Y}_{t}$ is an $n \times 1$ vector of contemporaneous variables, $\mathbf{B}(L)$ is a polynomial in the lag operator, $L$; and $\mathbf{U}_{t}$ is an $n \times 1$ vector of error terms with $\mathbf{U}=\left[\mathbf{U}_{t}\right], t=1,2, \ldots, T$.

It is said that there are no atheists in the foxhole. The battle for the VAR analyst is to use it for policy analysis, and that requires theoretical commitments. The problem is that the elements of $\mathbf{U}_{t}$ are typically intercorrelated - that is, the covariance matrix $\boldsymbol{\Omega}=$ $\mathrm{E}\left(\mathbf{U U}^{\prime}\right)$. is not diagonal. This means that the individual equations of the system are not causally distinct. They cannot be perturbed separately, which is what policy analysis requires. Sims initially dealt with this issue in an ad hoc fashion, suggesting that 
equation (1) could be orthogonalized using particular transformations (Choleski decompositions) without too much concern about which one. (His position reminds one of Dwight Eisenhower urging every American to worship ... at the church or synagogue of his choice.) Under criticism from Cooley and LeRoy (1985) and Leamer (1985), among others, Sims (1986) came to accept that some a priori structure had to be imposed on equation (1). In particular, this required a choice of $\mathbf{A}_{0}$ such that

$$
\mathbf{Y}_{t}=\mathbf{A}_{0}^{-1} \mathbf{A}(L) \mathbf{Y}_{t-1}+\mathbf{A}_{0}^{-1} \mathbf{E}_{t}=\mathbf{B}(L) \mathbf{Y}_{t-1}+\mathbf{U}_{t}
$$

where $\boldsymbol{\Sigma}=\mathrm{E}\left(\mathbf{E E ^ { \prime }}\right)$ is diagonal. The equation

$$
\mathbf{A}_{0} \mathbf{Y}_{t}=\mathbf{A}(L) \mathbf{Y}_{t-1}+\mathbf{E}_{t}
$$

is known as the structural VAR (SVAR).

Equation (1) can be estimated and, given $\mathbf{A}_{0}$, transformed into (3) From (3), it is possible to work out the response of the economy to various shocks. In general, there are many choices of $\mathbf{A}_{0}$ that will fulfill the conditions of equation (2). So, in general, an $a$ priori theoretical commitment remains necessary. But where the Cowles-Commission program typically imposed identifying constraints on both $\mathbf{A}_{0}$ and $\mathbf{A}(L)$, SVARs only place constraints on the contemporaneous causal relationships among the variables (i.e., on $\mathbf{A}_{0}$ ). The god of the Cowles-Commission program is not, then, dead after all, but still remains on life support - not least because the charge of incredibility that Sims leveled 
against structural models identified in the Cowles-Commission tradition applies equally to SVARs. The idea seems to be to have just enough faith to get you through the night.

\section{An Uneasy Alliance}

Both Lucas and Sims agree that the Cowles-Commission program, at least as implemented in the macroeconometric models of the 1960s and 1970s, was deficient. Yet the Lucas critique calls for a renewed dedication to a microtheoretical basis for macroeconomics, while the Sims critique calls for an atheoretical macroeconomics. Surprisingly, the two methodologies stand in a kind of uneasy alliance. Many adherents to Lucas's methodological views nevertheless employ SVARs in their research.

The relationship is two-way. In one direction, the use of SVARs is conditioned by the Lucas critique. One argument for using the SVAR was suggested early on by Sims (1982). He conceded that Lucas's argument was correct; nonetheless, if in practice changes of policy regime were infrequent or if they could be modeled as part of a superregime in which the current regime was a realization of knowable switching process between regimes, then the SVAR could be a stable representation of the economy. This argument accounts for one of the most puzzling features of SVAR analysis - the obsessive concern for policy shocks.

Typically, the effect of monetary or fiscal policy is analyzed in an SVAR by calculating the impulse-response function - that is, by tracing out the effect of a random shock to the policy equation on all the variables of the system over time. What is odd about this is that we do not normally think of policymakers as crafting policy through the delivery of random shocks. And, in practice, the residuals of the policy equations, which 
give an estimate of the size of the shocks, are quite small. We normally think of policymakers as trying to affect the economy through systematic reactions to changing conditions. In a Lucasian world of rapidly clearing markets, continuous full employment, and rational expectations, systematic monetary policy would not have any effects changing it would not matter - and shocks are the only thing that would have real effects. The world in which the SVAR is immune from the Lucas critique is also the world in which, from the policy point of view, it does not matter whether the equations of the SVAR are stable are not. Shock analysis is legitimate when it is useless.

Over time, however, even new classical macroeconomists have come to believe that markets do not clear perfectly or quickly and that there may be deviations from rational expectations. In theory, this gives policy a handle on the real economy. But then, if the Lucas critique is correct, any systematic change in the equations representing policy reactions should be reflected in structural breaks in other equations of the SVAR. When policy analysis is useful, the validity of the SVAR is questionable. Sims (1999) has conducted counterfactual experiments that amount to substituting one policy-reaction function for another in an SVAR. It is unclear, however, how that could be valid in the face of the Lucas critique.

The use of SVARs is conditioned by the Lucas critique. And in the other direction, users of calibrated models frequently turn to SVARs to validate the success of their models. An SVAR is estimated using the same variables as the calibrated model. Impulse-response functions are calculated from both the SVAR and the calibrated model. The model is judged a success if, qualitatively at least, it manages to mimic the impulseresponse functions of the SVAR. 
There is a strong element of casual empiricism in these exercises. Which variables are included in the SVAR depends not on which might be important in the world but on which happened to be elements for the calibrated model. Typically, these models are simultaneous, and do not possess a recursive causal ordering. Nevertheless, $\mathbf{A}_{0}$ is typically chosen to be a triangular matrix - that is, to have a well defined recursive causal ordering. This choice is usually arbitrary or justified by an appeal to considerations such as common-sense views on relative speeds of adjustment unrelated to the theoretical implications of the model. Such a lack of seriousness about how one should connect theoretical models to empirical methods shows how far away the VAR program is in practice from Fisher's experimental design. In that methodology, the omission of a control would result in an invalid experiment. In the Cowles-Commission framework, identifying assumptions are meant to take the place of such controls. That requires a tight mapping between theory and econometric model. Here the mapping is extremely loose.

In the end the alliance between the VAR program and the Lucasian microfoundational program is essentially incoherent. The root of the problem is the reigning Walrasian methodology.

\section{Two Visions}

\section{Walrasian Methodology}

When David Colander (1996, 2004) calls for a post-Walrasian economics, he appears to react primarily to the Walrasian vision of what economic theory should be. This is the familiar conception of economic atoms, each maximizing its utility and/or profit subject 
to technological and resource constraints. The characteristic which most marks the Walrasian system is the completely generalized interdependence among competitive markets. This vision may or may not be a good starting point for a theoretical account of the economy. I am less inclined to attack it than is Colander. Adherence to Walrasian theory in its commonly accepted sense, however, does not seem to me to be the root of the problem with macroeconometrics.

Instead, where macroeconometrics goes off the rails is in adhering to Walrasian methodology in something like the sense this term is used by Milton Friedman (1949, 1953, 1955). Friedman characterizes Walrasian methodology as seeking photographic accuracy in its representation of reality. This may not be the most felicitous way to put the matter; for Walrasian theory is itself highly abstract. But one sees the point. The Walrasian approach is totalizing. Theory comes first. And when it is applied to econometrics, it is taken in at the ground floor. Empirical reality must be theoretically articulated before it can be empirically observed. ${ }^{8}$ There is a sense that the Walrasian attitude is that to know anything, one most know everything. This attitude might be called apriorism. It is already present in the Cowles-Commission program, so that in some sense reactions to the Lucas critique are a kind of Cowles-Commission Puritanism.

Apriorism suffers from a fundamental problem. How do we come to our a priori knowledge? For Austrians, such as Mises (1966), it is not a problem, because economics is seen as a branch of deductive logic. But most macroeconomists expect empirical evidence to be relevant to our understanding of the world. If that evidence can be viewed only through totalizing a priori theory, it cannot be used to revise the theory.

\footnotetext{
${ }^{8}$ Walras was not an empirical economist and, so, may not be truly responsible for the attitude that I am calling "Walrasian” as it shows up in econometrics.
} 
Even though there is no necessary connection between the content of Walrasian theory and the Walrasian totalizing methodology, it is not accidental that the new classical macroeconomics wedded itself so thoroughly to Walrasian theory. If one must commit a priori to some theory, it is likely to be the one that captures the age-old concerns of economics - responses of self-interested individuals to incentives in markets - in the most tractable and highly developed form. The methodological Walrasian needs theoretical conviction in order to carry out his empirical agenda. The irony is that the representative-agent version of Walrasian theory is neither faithful to the underlying microeconomic theory nor coherent in its own right. In an sense, it suffers from its own Sims critique: the restrictions that would allow one to move from Walrasian microeconomics to an aggregate Walrasian model are literally incredible (more on this in Section IV).

\section{Marshallian Methodology}

The distinction between Walrasian and Marshallian methodology has been promoted most notably by Friedman. We draw heavily on Friedman's view of what it means to be Walrasian even as we qualify his characterization slightly. There is no need to qualify his characterization of Marshall, which is drawn nearly verbatim from Marshall's essay, “The Present Position of Economics” (1885).

Walras started his intellectual life as an engineer. The Walrasian vision is an engineering vision. The Walrasian wants to articulate the causal structures of the economy. The modern Walrasian macroeconomist wants microfoundations for macroeconomics. Here the metaphor of foundations is seen through the eyes of the 
engineer. The foundations are where we start building. If we do not get them right, the superstructure will be shaky.

The Marshallian also wants microfoundations. But the metaphor is a different one. The Marshallian approach is archaeological. We have some clues that a systematic structure lies beneath the complexities of economic reality. The problem is to lay this structure bare. To dig down to the find the foundations, modifying and adapting our theoretical understanding as new facts accumulate, becoming ever more confident in our grasp of the superstructure, but never quite sure that we have reached the lowest level of the structure.

The Marshallian approach is not atheoretical. Marshall writes:

[F]acts by themselves are silent. Observation discovers nothing directly of the action of causes, but only sequences in time [Marshall 1885, p. 166] . . . [T] he most reckless and treacherous of all theorists is he who professes to let the facts and figures speak for themselves ... [p. 168]

Economic theory is "not a body of concrete truth, but an engine for the discovery of concrete truth” (Marshall 1885, p. 159). Again, Marshall writes that economic theory provides "systematic and organized methods of reasoning” [p. 164] and an account of “manner of action of causes" [p. 171].

While theory is ideally universal - not unlike Lucas's vision of a theory without free parameters - theory is, in practice incomplete and probationary. Theory must be supplemented with particular facts to be useful. This is not, as some modern economists would have it, invidious ad hockery; it is an inevitable part of the process of acquiring empirical knowledge.

\section{Marshallian Macroeconometrics}




\section{Synthetic Microanalysis}

Robert Lucas has profoundly shaped modern macroeconomics. Only the wildly heterodox dare express skepticism about the necessity for microfoundations for macroeconomics. What is surprising is just how flimsy the representative-agent microfoundations that macroeconomists commonly demand really are. Microeconomic theorists are well aware that the conditions needed to aggregate systematically to representative production, utility (or demand) functions are simply too stringent to be fulfilled in actual economies (see, for example, Kirman 1992 or Felipe and Fisher 2003). Yet, support for such pseudo-microfoundations remains solid in the profession.

The appeal of microfoundations is largely ontological: everyone agrees that the economy is composed of individuals making choices subject to constraints. The operative question, however, is: can the aggregate outcomes be inferred from detailed knowledge of individuals? The practical answer is clearly no. No one has proposed an analysis of macroeconomic aggregates that truly begins with individuals. Who would know how? Is this because the problem is just too difficult? Or is it because it cannot be done in principle? The advocate of the representative-agent model implicitly believes the former. I have argued elsewhere that macroeconomic aggregates are emergent phenomenon that belong to different categories even than similarly named microeconomic concepts, and that, in principle, one cannot reduce the macro to the micro (Hoover 2001, ch. 5).

The physicist-turned-philosopher, Sunny Auyang (1998), points out than economics and physics face analogous problems. Quantum physicists are reductionist. They typically believe that the microstructure of reality, revealed by particles in isolation, 
not only accounts for the existence of aggregate macrophysical phenomena, but that one could, at least in principle, work out the characteristics of the macrophysical phenomena from quantum principles. Solid state physicists, on the other hand, typically argue for the autonomy of their own macrophysical concepts and do not believe that reduction is possible. Auyang appeals to complexity theory to explain how the macrophysical reality could both be deterministically related to the microphysical reality and, yet, solid-state physics not be reducible, even in principle, to quantum physics.

Yet, Auyang believes that the gulf between the micro and the macro in physics or economics is not completely unbridgeable in the sense that what happens at the micro level must matter for the macro level. She makes the case for what she refers to as synthetic microanalysis. Synthetic microanalysis essentially replaces the engineering, bottom-up approach of the microreductionist with an archaeological, top-down approach. It is, in this sense, a Marshallian methodology. Macro phenomena are analyzed into simpler components. That is microanalysis. But why "synthetic"? First, there is no reason to believe that the theoretical structures identified map onto the most fundamental ontological building blocks of reality. Theorizing is the construction of models for purposes. Models propose different ways of disjointing a seamless reality for different purposes. They emphasize some particularly important feature and look for ways to suppress complications that may be irrelevant to the problem at hand. They are not independent of empirical fact, but they can arrange the facts in ways that suit different purposes and that may sometimes appear to be incompatible with each other. Synthetic microanalysis is compatible with realism, but rejects what the philosopher Paul Teller 
(forthcoming) refers to as the "perfect-model model.” There are good models and bad models, but models are literally ad hoc - that is built for the purpose at hand.

One need not accept that the gulf between the micro and macro is in principle unbridgeable to agree that it is so in practice. In that, the microreductionist quantum physicist, Richard Feynman agrees completely with Auyang. Feynman (1995, p. 114) argues that “'solid-state physics' or 'liquid-state physics' or 'honest physics' cannot be derived from elementary analysis of the constituent particles - their relationships are too many and too complex. Practically, economics is in the same boat, and it does little good to pretend that we can do so, in principle, and that, therefore, the representative-agent model, which mimics the mathematical methods of microeconomics, but which is not microeconomics in substance, should be regarded as the standard for macroeconomics. If we wish to understand what lies beneath macroeconomic phenomenon, we need to adopt the attitude of synthetic microanalysis and dig. 


\section{Econometric Examples}

What kind of macroeconometrics is compatible with synthetic microanalysis? What might Marshallian econometrics look like? I will try to hint at an answer with some illustrations.

First, consider VAR analysis. As we saw in earlier sections, VAR analysis started off as an atheoretical approach - macroanalysis without any ambitions to connect to the microeconomic. It then discovered that it required minimal structure. Subsequently, the practices of VAR analysis have been heavily conditioned by the assumptions of Lucasian microfoundations, even when those have been abandoned by theoretical macroeconomists. John Cochrane (1998) points out the cognitive dissonance experienced by macroeconomists who believe that some agents follow rules of thumb or that prices are sticky and, yet, analyze SVARs as if the world were populated only by agents with rational expectations operating in clearing markets. Cochrane offers an example of synthetic microanalysis - a small step toward the underlying structural behavior behind the VAR without the pretence of bedrock individual tastes and technology.

Cochrane proposes an aggregate supply relationship:

$$
y_{t}=\Psi(L)\left[\lambda m_{t}+(1-\lambda)\left(m_{t}-E\left(m_{t} \mid \Omega_{t-1}\right)\right]+\mathbf{D}(L) \boldsymbol{\varepsilon}_{w t},\right.
$$

where $y_{t}$ denotes an output measure that belongs to a vector of non-monetary variables $\boldsymbol{w}$, $m_{t}$ denotes a monetary policy indicator, $E(. \mid$.$) is the conditional expectations operator, \Omega_{t-1}$ is the information available at time $t-1$, and $\boldsymbol{\varepsilon}_{w t}$ is a vector of orthogonalized, non- 
monetary innovations (which include the output innovation itself). ${ }^{9}$ The term $\Psi(L)$ is a polynomial in the lag operator $L$ (e.g., $L^{\alpha} x_{t}=x_{t-\alpha}$ ). $\mathbf{D}(L)$ is polynomial vector in the lag operator. The parameter $\lambda$ takes values between 0 and 1 .

When $\lambda=0$, equation (4) is the famous Lucas surprise-only supply curve (see Hoover 1988). In an economy with a Lucas supply curve, rational expectations, and clearing markets, systematic monetary policy does not affect output. When $\lambda=1$, then equation (4) can be interpreted as the supply curve of an economy with rule-of-thumb consumers. ${ }^{10}$ In such an economy, systematic monetary policy does affect real output. When $\lambda$ takes any other value, systematic monetary policy matters, but to different degrees. Cochrane (1998) shows - if we only knew the value of $\lambda$ - how to relate the coefficients of equation (4) (embedded in the lag functions $\Psi(L)$ and $\mathbf{D}(L)$ ) to the estimated parameters of an SVAR such as equation (3) repeated here:

$$
\mathbf{A}_{0} \mathbf{Y}_{t}=\mathbf{A}(L) \mathbf{Y}_{t-1}+\mathbf{E}_{t}
$$

The effects of policy on the real economy differ, depending on the value of $\lambda$.

When $\lambda=0$, a shift in policy parameters (the coefficients of the policy-reaction function that governs the behavior of $m_{t}$ ) would result in structural breaks in the output equation of the SVAR, equation (3). This is an example of the Lucas critique:

macroeconometric relationships are not invariant in the face of policy shifts. But it really does not matter, systematic policy is ineffective, so the SVAR is not useful for policy

\footnotetext{
${ }^{9}$ The notation has been alter slightly from Cochrane (1998).

${ }^{10}$ Cochrane (1998) also develops an identifying model with sticky prices that has much the same practical consequences for the influence of systematic monetary policy as one with some rule-of-thumb consumers.
} 
anyway. When $\lambda=1$, the parameters of the policy-reaction function will not play any part in the output equation of the SVAR, so that it remains stable in the face of a change in systematic policy and, in fact, measures the effect of policy on output. The irony is that the Lucas critique matters most when policy is least effective, and matters least when policy is most effective.

Cochrane (1998) argued that $\lambda$, the fraction of rule-of-thumb agents, could not be identified. Hoover and Jorda (2001) show how it can be identified from using information from distinct monetary-policy regimes. Such identification requires that equation (4) be accepted as an a priori identifying assumption.

The first thing to notice is that equation (4) lacks a microfoundation - it is not derived from optimization given deep tastes and technology, either from a disaggregated microeconomic model or from a representative-agent model. One could argue that, in principle, the coefficients of $\Psi(L)$ itself would be subject to the Lucas critique (see Cochrane 1998, p. 283). It does, however, take a step toward articulation of the structure underlying the VAR: it models the effects of a population of two classes of agents (those with rational-expectations and those without) in a manner that would be compatible with a variety of particular models falling into broad classes.

Marshallian macroeconometrics in this case starts with some tentative theoretical presuppositions and asks, how well they do when confronted with the data? For example, the salience of the Lucas critique can be checked by examining the invariance or lack thereof of the estimated parameters of the model. Hoover and Jorda (2001) discovered some evidence for the Lucas critique in that they estimated value of $\lambda=0.57$. Yet even at that value, which implies a close-to-even split between "rational” and rule-of-thumb 
agents, it can be shown through simulation that the economy would behave nearly the same as if it were completely populated by the rule-of-thumb agents. ${ }^{11}$ The theoretical presuppositions help us to learn something about the data and to render it more useful for policy analysis, but the data also provide a check on those presuppositions. They may suggest areas in which the theory could be elaborated to better account for features of the data. For example, do either the formation of rules-of-thumb or of the ability to construct rational expectations depend on learning behavior?

Cochrane's analysis of the monetary policy highlights the interplay of a theoretical model (e.g., equation (4)) and a particular characterization of the data (e.g., equation (3)). North American macroeconomics has focused more on developing theory subject certain criteria than on the quality of the characterization of the data. In contrast, Spanos (1995) argues for an approach to econometrics that he calls probabilistic reduction. The essential point is to maximize the salience of the econometric model by searching for a representation of the data that extracts the maximal amount of statistical information from it. That representation of the data then provides a better basis on which to exercise the interpretative transformations of economic theory.

The data side of Cochrane's analysis could be addressed in the spirit of Spanos's approach. We have already commented on the arbitrariness of the identifying assumptions of the structural VAR - that is, the restrictions on $\mathbf{A}_{0}$. It is widely believed by VAR practitioners that these restrictions are arbitrary and must come from theory. But, in fact, there may be statistical grounds for selecting these restrictions, at least in some cases, based on the graph-theoretic analysis of causation. ${ }^{12}$

\footnotetext{
${ }^{11}$ Estrella and Fuhrer (1999) provide related evidence that the Lucas critique is not practically important.

${ }^{12}$ Hoover (2004b) provides a concise introduction to graph-theoretic methods of causal inference.
} 
A simple example, shows the key points. We can think of $\mathbf{A}_{0}$ as placing a set of restrictions on the variables in $\mathbf{Y}$. To illustrate, let $\mathbf{Y}=\left[\begin{array}{c}W \\ X \\ Y \\ Z\end{array}\right]$ and let $\mathbf{A}_{0}=\left[\begin{array}{cccc}1 & 0 & 0 & 0 \\ \alpha_{X W} & 1 & 0 & 0 \\ 0 & 0 & 1 & 0 \\ \alpha_{Z W} & 0 & \alpha_{Z Y} & 0\end{array}\right]$, where the $\alpha_{i j}$ can be thought of as the coefficients of regression equation, so that, for example, the last line corresponds to $Z=\alpha_{Z W} W+\alpha_{Z Y} Z+$ error. A regression equation can be regarded as having the arrow of causation pointed from the right-hand to the left-hand side (see Hoover 2001, p. 39, Cartwright 1989, p. 18, Pearl 2000). The causal relationships among the variables can be represented by a diagram (Figure 1) that is isomorphic to the relationships in $\mathbf{A}_{\mathbf{0}}$.

\section{Figure 1}

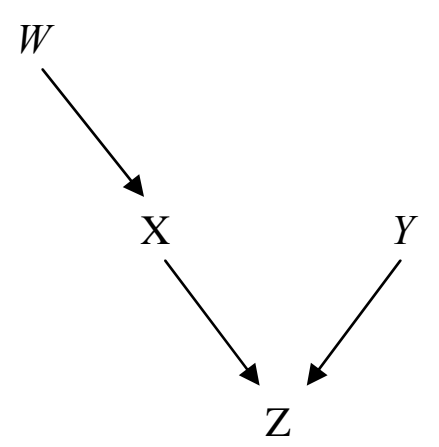

Graph-theory has been applied to such diagrammatic representations of causal structure by Pearl (2000) and Sprites, Glymour, and Scheines (2000) among others. They have established an isomorphism between causal relationships expressed in a graph and 
properties of statistical independence among data. In this case, $X$ is an intervening cause between $W$ and $Z$. If Figure 1 is the complete relevant universe, then $W$ and $Z$ are statistical dependent when considered as a pair, but statistically independent conditional on $X$. In constrast, $X$ and $Y$ are statistically independent when considered as a pair, but statistically dependent conditional on $Y$. Causal search algorithms work backwards from these patterns of statistical independence to find the class of graphs (and therefore the restrictions on $\mathbf{A}_{\mathbf{0}}$ ) that are consistent with them. Sometimes, the class has only a single member. In that case, data identify $\mathbf{A}_{\mathbf{0}}$ without an appeal to prior theory. In other cases, the class has multiple members, but statistics may nonetheless reduce the work left for the identifying theory to do. Swanson and Granger (1997) show how to apply these methods to a VAR. Demiralp and Hoover (2004) extend Swanson and Granger's search method and provide a Monte Carlo analysis of its effectiveness.

Spanos sees his approach as tracing ultimately to the biometric tradition of Galton and Pearson. It is also closely related to what might be called the London School of Economics (LSE)/Copenhagen School. The LSE approach is often traced to the work of Denis Sargan, but is most clearly associated with David Hendry and a large number of co-workers (see Mizon 1995 for a survey). What I am calling the Copenhagen approach is the approach exemplified in the work of Katarina Juselius and Søren Johanssen (see Juselius 1999 and Juselius and Johansen 2004 in this volume for a methodological exposition).

Hendry has for many years advocated a "general-to-specific approach” to econometrics. The essence of his approach is to provide as broad a characterization of the data as possible - a general model - to be used as benchmark to test down to a simple 
model that carries the irreducible statistical information of the general model in a more parsimonious form. An acceptable simple model must meet stringent statistical specification criteria (including desirable properties for residuals and stability of coefficients), and it must statistically encompass both the general model and alternative simplifications. Recently Hendry and Krolzig (1999) have incorporated many of the practices of LSE econometrics into an expert system, PCGets (Hendry and Krolzig 2001). ${ }^{13}$

The Copenhagen approach has focused on the characterization of the long-run properties of time-series data - its integration and cointegration properties. It has long been known that the statistics typically used in econometrics up to the 1980s was not suitable to nonstationary data. The Copenhagen approach is again a species of probabilistic reduction, decomposing time-series data into variables which move together in the long run (cointegrate) and the common trends that drive them.

There are many detailed connections between the LSE and Copenhagen approaches in their history; and their practices are strongly complementary. It is natural, therefore, to group them together. Where typically both approaches impose less prior theory than the approach to SVARs illustrated by Cochrane's policy analysis, they insist on much stronger statistical criteria. They fit very nicely into a Marshallian methodology, because, by establishing much more highly defined characterizations of the data than does the typical VAR, they can place restrictions on what characteristics an acceptable theory must have. In some cases, they may allay theoretical concerns. The Lucas critique, for instance, can be seen as a possibility theorem: if the economy is

\footnotetext{
${ }^{13}$ Hoover and Perez (1999), which initiated Hendry and Krolzig's development of PcGets, provides a Monte Carlo evaluation of a related expert system; see also Hoover and Perez (2004).
} 
structured in a certain way, then aggregate relations will not be invariant to changes in systematic policy. Tests of superexogeneity, based in LSE methods, have been used to test whether invariance fails in the face of policy change (for a survey, see Ericsson and Irons 1995). That it does not in many cases provides information that the economy is not structured in the way that Lucas contemplates.

\section{After Walrasian Econometrics}

It is easy to complain about the failures of orthodox macroeconomics and to lay the blame on its particular narrow Walrasian theoretical conception and to see progress in greater openness to a more realistic theory. But I suggest a different diagnosis. The problem is not in Walrasian theory, but in the Walrasian attitude of apriorism. The moral problem of science is how, in the phrase of the great pragmatist philosopher C.S. Peirce (1934-58), to fix belief. The failure of the Cowles-Commission program in the 1970s was less from its supposed predictive failure or the failure of its models to be invariant to policy, than from a lack of conviction on the part of macroeconomists in the soundness of its identifying assumptions. Sims responded by trying to live without theoretical convictions, but with limited success. Lucas tried to find conviction in a zealous commitment to Walrasian theory. Lucas carried the day; but, as with other cases of zealotry, there is a gap between the ideal (a macroeconomics built from individual microeconomic behaviors) and the practice (a macroeconomics that mimics the forms of microeconomics, but never deals with individuals). This zealotry has been damaging to empirical macroeconomics because it dismisses particular, useful empirical 
investigations, not because they are not informative, but because they do not appear in appropriate dress.

I doubt, however, that a post-Walrasian program that replaces Walrasian theory with some supposedly richer or more realistic theory will do any better. A philosophy of “anything goes” and low expectations for the possibility of discriminating between competing conclusions on a principled basis are not calculated to produce conviction or fix belief. They cannot produce a stable economics - scientifically or sociologically. Marshallian methodology seems more calculated to fix belief and to produce workable conviction. Yes, we must start with whatever theoretical understanding we have at the moment. But all theory is tentative. It must be rigorously confronted with data. Theory and data must be mutually adjusted. Marshallian econometrics is possible, either in the familiar North American VAR framework and in the European LSE/Copenhagen framework. It is not Walrasian, because it does not start with the premise that to know anything one must know everything. It is Marshallian, not because of its specific content, but because of its attitude: to know anything, you have to dig. 


\section{References}

Adelman, Irma and Frank L. Adelman. (1959) “The Dynamic Properties of the KleinGoldberger Model,” Econometrica 27, 596-625.

Auyang, Sunny M. (1998) Foundations of Complex-System Theory in Economics, Evolutionary Biology, and Statistical Physics. Cambridge: Cambridge University Press.

Cartwright, Nancy. (1989) Nature's Capacities and Their Measurement. Oxford: Clarendon Press.

Cochrane, John H., (1998), "What Do the VARs Mean? Measuring the Output Effects of Monetary Policy," Journal of Monetary Economics 41, 277-300.

Colander, David. (2004) "Post Walrasian Macro Policy and the Economics of Muddling Through,” unpublished typescript.

Colander, David and Hans van Ess. (1996) "Post Walrasian Macroeconomic Policy” in David Colander (ed.) Beyond Micro Foundations: Post Walrasian Macroeconomics. Cambridge: Cambridge University Press.

Cooley, Thomas F. and Stephen F. LeRoy. (1985) "Atheoretical Macroeconomics: A Critique,” Journal of Monetary Economics vol. 16, 283-308.

Demiralp, Selva and Hoover, Kevin D . (2004) "Searching for the Causal Structure of a Vector Autoregression,” Oxford Bulletin of Economics and Statistics 65, 745-767.

Dysan, Freeman. (2004) “The World on a String,” New York Review of Books 51(8), 13 May, 16-19.

Ericsson, Neil and John Irons. (1995) "The Lucas Critique in Practice: Theory Without Measurement,” in Kevin D. Hoover (ed.) Macroeconometrics: Developments, Tensions and Prospects. Boston: Kluwer, pp. 263-312.

Estrella, Arturo and Jeffrey C. Fuhrer (1999) “Are "Deep" Parameters Stable? The Lucas Critique as an Empirical Hypothesis,” Federal Reserve Bank of Boston, Working Paper No. 99-4

Felipe, Jesus and Franklin M. Fisher. (2003) “Aggregation in Production Functions: What Applied Economists Should Know,” Metroeconomica 54, 208-262.

Feynman, Richard. (1995) Six Easy Pieces: Essentials of Physics Explained by Its Most Brilliant Teacher. Reading, MA: Addison-Wesley.

Friedman, Milton. 1949. The Marshallian Demand Curve. Journal of Political Economy 57, 463-495

Friedman, Milton. 1953. The Methodology of Positive Economics. In Essays in Positive Economics. Chicago: Chicago University Press, pp 3-43.

Friedman, Milton. (1955) "Leon Walras and His Economic System: A Review Article," American Economic Review 45, 900-909.

Frisch, Ragnar. (1933) “Editor's Note.” Econometrica 1, pp. 1-4. 
Haavelmo, Trygve. (1944) “The Probability Approach in Econometrics,” Econometrica 12 , supplement.

Hansen, Lars Peter and Thomas J. Sargent. (1980) "Formulating and Estimating Dynamic Linear Rational Expectations Models,” Journal of Economic Dynamics and Control 2, 7-46. .

Hartley, James E., Kevin D. Hoover and Kevin D. Salyer, editors. (1998) Real Business Cycles: A Reader. London: Routledge.

Hendry, D. F. and Krolzig, H.-M. (1999). 'Improving on “Data mining Reconsidered” by K.D. Hoover and S.J. Perez’, Econometrics Journal 2, 202-218.

Hendry, D. F. and Krolzig, H.-M. (2001) Automatic Econometric Model Selection Using PcGets 1.0, Timberlake Consultants, London.

Hood, W.C. and T.C. Koopmans. (1953) (eds.) Studies in Econometric Method, Cowles Commission Monograph 14. New York: Wiley.

Hoover, Kevin D. (1988) The New Classical Macroeconomics. Oxford: Blackwell.

Hoover, Kevin D. (1995) "Facts and Artifacts: Calibration and the Empirical Assessment of Real-Business-Cycle Models,” Oxford Economic Papers 47, 24-44.

Hoover, Kevin D. (2001) Causality in Macroeconomics. Cambridge: Cambridge University Press.

Hoover, Kevin D. (2004a) “Lost Causes,” Journal of the History of Economic Thought 26, 149-164.

Hoover, Kevin D. (2004b) “Automatic Inference of the Contemporaneous Causal Order of a System of Equations,” Econometric Theory, forthcoming.

Hoover, Kevin D. and Oscar Jorda (2001). “Measuring Systematic Monetary Policy,” Federal Reserve Bank of St. Louis Review 83, 113-138.

Hoover, Kevin D. and Stephen J. Perez. (1999a). “Data Mining Reconsidered:

Encompassing and the General-to-Specific Approach to Specification Search,” Econometrics Journal 2, 167-91.

Hoover, Kevin D. and Stephen J. Perez. (2004) "Truth and Robustness in Cross-country Growth Regressions,” Oxford Bulletin of Economics and Statistics, forthcoming.

Ingram, Beth Fisher. (1995) "Recent Advances in Solving and Estimating Dynamic Macroeconomic Models,” in Kevin D. Hoover (ed.) Macroeconometrics: Developments, Tensions, and Prospects. Dordrecht: Kluwer, pp. 15-46.

Juselius, Katarina. (1999) "Models and Relations in Economics and Econometrics," Journal of Economic Methodology 6, 259-290.

Juselius, Katarina and Søren Johansen. (2004) "Extracting Information from the Data: A Popperian View on Empirical Macro,” in the current volume.

Kirman, A.P. (1992) "Whom or What Does the Representative Agent Represent?" Journal of Economic Perspectives 6, 117-136. 
Koopmans, T.C. (1950) Statistical Inference in Dynamic Economic Models, Cowles Commission Monograph 10. New York: Wiley.

Kydland, Finn E. and Edward C. Prescott. (1982) "Time to Build and Aggregate Fluctuations,” Econometrica 50, 1345-69.

Leamer, Edward E. (1985) "Vector Autoregressions for Causal Inference,” in Karl Brunner and Allan H. Meltzer (eds.) Understanding Monetary Regimes. CarnegieRochester Conference Series on Public Policy, Vol. 22, Spring. Amsterdam: NorthHolland, pp. 225-304.

Lucas, Robert E. Jr. (1976) "Econometric Policy Evaluation: A Critique," in Karl Brunner and Allan H. Meltzer (eds.) The Phillips Curve and Labor Markets. Carnegie-Rochester Conference Series on Public Policy, vol. 11, Spring. Amsterdam: North-Holland, pp. 161-168.

Lucas, Robert E., Jr. (1977) “Understanding Business Cycles,” in Robert E. Lucas, Jr. (1981) Studies in Business Cycle Theory. Oxford: Blackwell, pp. 215-239.

Lucas, Robert E., Jr. (1980) "Methods and Problems in Business Cycle Theory," in Studies in Business-Cycle Theory. Oxford: Blackwell, 1981.

Lucas, Robert E., Jr. (1987) Models of Business Cycles. Oxford: Blackwell.

Marschak, Jacob. (1953) “Economic Measurements for Policy and Predictions,” in W. C. Hood and T. C. Koopmans (eds.) Studies in Econometric Method, Cowles Foundations Monograph no. 14. New York: Wiley.

Marshall, Alfred. (1885) “The Present Position of Economics,” in A.C. Pigou (ed.) Memorials of Alfred Marshall. London: Macmillan, 1925, pp. 152-174.

Mises, Ludwig von. (1966) Human Action, $3^{\text {rd }}$ ed. Chicago: Regnery.

Mizon, Grayham E. (1995) "Progressive Modelling of Economic Time Series: The LSE Methodology,” in Kevin D. Hoover (ed.) Macroeconometrics: Developments, Tensions and Prospects. Boston: Kluwer, pp. 107-170

Morgan, Mary S. (1990) The History of Econometric Ideas. Cambridge: Cambridge University Press.

Pearl, Judea. (2000). Causality: Models, Reasoning, and Inference, Cambridge University Press, Cambridge.

Peirce, Charles S. (1934-58) Collected Papers of Charles Sanders Peirce, vol. 5, Charles Hartshorne and Paul Weiss, editors. Cambridge, MA: Belknap Press, pp. 377-387.

Prescott, Edward C. (1986) "Theory Ahead of Business Cycle Measurement," Federal Reserve Bank of Minneapolis Quarterly Review, 10, 9-22.

Simon, Herbert A. (1953) "Causal Ordering and Identifiability," in Herbert A. Simon, Models of Man. New York: Wiley 1957, ch. 1.

Sims, Christopher A. (1980). "Macroeconomics and Reality," Econometrica 48, 1-48.

Sims, Christopher A. (1982). "Policy Analysis with Econometric Models,” Brookings Papers on Economic Activity, pp. 107-152.

Sims, Christopher A. (1986) "Are Forecasting Models Usable for Policy Analysis?" Federal Reserve Bank of Minneapolis Quarterly Review 10(1), Winter, 2-15. 
Sims, Christopher A. (1999) "The Role of Interest Rate Policy in the Generation and Propagation of Business Cycles: What Has Changed Since the '30s?” In Jeffrey C. Fuhrer and Scott Schuh, editors. Beyond Shocks: What Causes Business Cycles. Federal Reserve Bank of Boston Conference Series, no. 42, pp. 121-160.

Spanos, Aris. (1995) “On Theory Testing in Econometrics: Modeling with Nonexperimental Data,” Journal of Econometrics 67, 189-226.

Spirtes, Peter, Clark Glymour, and Richard Scheines. (2000) Causation, Prediction, and Search, $2^{\text {nd }}$ edition. Cambridge, MA: MIT Press.

Stigler, Stephen M. (1986) The History of Statistics: Measurement of Uncertainty Before 1900. Cambridge, MA: Belknap Press.

Swanson, Norman R. and Clive W.J. Granger. (1997). 'Impulse response functions based on a causal approach to residual orthogonalization in vector autoregressions', Journal of the American Statistical Association 92, 357-67.

Teller, Paul. (forthcoming) “Twilight of the Perfect Model Model,” Erkenntis, forthcoming. 